\title{
Differential regulation of IGF-I, its receptor and GH receptor mRNAs in the right ventricle and caval vein in volume-loaded genetically hypertensive and normotensive rats
}

\author{
A Wickman, J Isgaard ${ }^{1}$, M A Adams ${ }^{2}$ and P Friberg \\ Department of Physiology, Institute of Physiology and Pharmacology, University of Göteborg, Göteborg, Sweden \\ ${ }^{1}$ Department of Internal Medicine, Research Center for Endocrinology and Metabolism, University of Göteborg, Göteborg, Sweden \\ ${ }^{2}$ Department of Pharmacology/Toxicology, Queens University, Kingston, Ontario, Canada \\ (Requests for offprints should be addressed to J Isgaard, Department of Internal Medicine, Research Center for Endocrinology and Metabolism, \\ University of Göteborg, Sahlgren's Hospital, S-413 45 Göteborg, Sweden)
}

\begin{abstract}
It has been suggested, mainly by in vitro findings, that cardiovascular tissue in the spontaneously hypertensive rat (SHR) should be more prone to proliferate/hypertrophy than that of the Wistar-Kyoto rat (WKY). The present study tests the hypothesis that the tissue of the lowpressure compartment in SHR, being structurally similar to that of the WKY, shows an increased growth response due to activation of the GH-IGF-I system.

An aortocaval fistula (ACF) was induced in 64 SHR and WKY male rats and 44 rats served as controls. They were all followed for 1, 2, 4 and 7 days after surgery. In separate groups of SHR $(n=4)$ and WKY $(n=3)$, central venous pressure was measured by telemetry recordings prior to opening of the fistula and for up to $16 \mathrm{~h}$ post-surgery. Systolic blood pressure was measured during the week postsurgery. The right ventricular (RV) and the caval vein IGF-I mRNA and RV IGF-I receptor and GH receptor mRNAs were quantitated by means of solution hybridisation assay.

In rats with ACF the systolic blood pressure decreased, approximately 29\% in SHR and 16\% in WKY between 1
\end{abstract}

and 7 days post-surgery $(P<0 \cdot 05, n=5-6$ in each group). SHR with ACF showed a transient elevation in central venous pressure vs WKY. Within the week following fistula induction both strains showed a similar, pronounced increase in RV hypertrophy. SHR with ACF showed a smaller, or even blunted, overall response with respect to activation of the GH-IGF-I system compared with WKY, the latter showing clear-cut elevation of gene expressions. Two days after shunt opening in SHR, RV and caval vein IGF-I mRNA increased by $57 \%$ and $108 \%(P<0 \cdot 05$ for both, $n=5-6$ in each group) respectively, and these expressions were then turned off, whereas RV GH receptor and IGF-I receptor mRNA expression remained unaffected compared with WKY rats. WKY rats showed on average a later and a greater response of GH-IGF-I system mRNA expression vs SHR.

The present in vivo study suggests that the SHR requires less activation of the GH-IGF-I system for creating a given adaptive structural growth response.

Journal of Endocrinology (1999) 161, 263-271

\section{Introduction}

The spontaneously hypertensive rat (SHR) shows that adaptive structural changes occur in the left ventricle (LV) and the resistance vessels both in the early stage and during the development of hypertension (Folkow 1982, Adams et al. 1989, Korner et al. 1989). In contrast, the right ventricle $(\mathrm{RV})$ shows no signs of hypertrophy compared with that in normotensive rats (Friberg 1985, Oka et al. 1993, Dilley et al. 1994).

In SHR, both an increase in number (Mulvany et al. 1985) and size of vascular smooth muscle cells (VSMC) have been suggested to be responsible for the augmented blood vessel wall mass (Owens \& Schwartz 1982). Several in vitro studies have demonstrated that VSMC cultured from SHR aorta replicate faster, and these cells have also been shown to possess increased responsiveness to growth factors (Hadrava et al. 1989, Scott Burden et al. 1989, Bukoski et al. 1991, Saltis et al. 1993, Grammas et al. 1994), as well as being less responsive to the growthinhibitory transforming growth factor- $\beta 1$ (TGF- $\beta 1$ ) than cells from Wistar-Kyoto rats (WKY) (Hamet et al. 1991, Saltis \& Bobik 1992, Saltis et al. 1992a, Tremblay et al. 1992, Agrotis et al. 1993, Sato et al. 1995). The question whether an exaggerated cardiovascular growth potential in SHR occurs also in vivo is difficult to study, since the 'structural baseline' is already offset compared with normotensive rats. Nevertheless, Dilley et al. (1994) demonstrated that VSMC in SHR are more reactive to growth stimuli induced by two-kidney, one-clip (2K1C) renal 
hypertension, corroborating in vitro data (Bukoski et al. 1991, Hamet et al. 1991, Saltis \& Bobik 1992, Saltis et al. 1992a,b, 1993, Tremblay et al. 1992, Agrotis et al. 1993, Grammas et al. 1994, Sato et al. 1995). Likewise, LV weight increased to a greater magnitude in renal hypertensive SHR vs WKY-2K1C, despite a smaller relative increase in systolic blood pressure (SBP) (Dilley et al. 1994), supporting previous findings (Friberg \& Nordborg 1986). Considered collectively, these in vitro and in vivo findings may indicate an accelerated growth potential in hearts and VSMC in SHR for a given stimulus compared with normotensive rats.

Given that previous work in SHR, with regard to cell growth, has focused mainly on the LV and in vitro 'arterial' cell culture systems, little is known about in vivo growth responses of the RV and the low-pressure compartment during increased haemodynamic demand. The RV and caval vein in SHR are apparently similar with regard to weight to those in WKY, and there is no difference at baseline either in central venous pressure (CVP) and right atrial pressures, or in neurohumoral factors, such as noradrenaline and the reninangiotensin system, between the strains (Oka et al. 1993).

Circulatory alterations, induced by an aortocaval fistula (ACF), involve increased volume flow from the arterial to the venous compartment, resulting in a widening of the caval vein and the RV. As a result using the ACF model in normotensive rats (Garcia \& Diebold 1990), an increased early expression of both the insulin-like growth factor-I (IGF-I) and the growth hormone $(\mathrm{GH})$ receptor mRNAs in the RV and caval vein, respectively, has been demonstrated (Isgaard et al. 1994, Wickman et al. 1997), supporting the contention that the over-expression of the GH-IGF-I system may be mediated via increased mechanical loading. Although it is important to acknowledge the role for other growth factors, besides the IGF-I and the GH-IGF-I system, these latter components have been strongly implicated in cardiovascular tissue growth (Lever \& Harrap 1992, Ito et al. 1993, Friberg et al. 1995). To test the hypothesis that the SHR also in the low-pressure compartment, being structurally similar to that of the WKY, demonstrates increased tissue growth for a given stimulus, the present study characterises, in the ACF model applied to both SHR and WKY: (i) magnitude and time-course of changes in RV weight in relation to the expression of GH-IGF-I system components (IGF-I, IGF-I receptor and GH receptor mRNAs) in the RV and the inferior caval vein respectively and (ii) immediate changes in CVP (radio-telemetry) as well as in SPB (tail-cuff technique).

\section{Materials and Methods}

\section{Surgical procedures}

Animals Age-matched SHR and WKY male rats were obtained from Möllegaard Breeding Center Ltd (Ejby,
Denmark). The animals arrived 1 week prior to experimentation. They had free access to standard pellet chow and tap water throughout the study. All experiments were approved by the Regional Animal Ethics Committee in Göteborg.

ACF During short-lasting barbiturate anaesthesia $\left(75 \times 10^{-3} \mathrm{~g} / \mathrm{kg}\right.$ body weight i.p. methohexital sodium; Brietal; Eli-Lilly and Co., Indianapolis, IN, USA), an ACF was created in SHR and WKY $(n=8$ for both strains at each time-point) rats weighing approximately $180 \mathrm{~g}$, by means of a fistula between the aorta and the inferior caval vein (Garcia \& Diebold 1990). The abdominal aorta was punctured with a 18 gauge disposable needle and advanced into the inferior caval vein. After withdrawing the needle, the puncture site was sealed with cyanoacrylate glue. Before closing the abdomen, the patency of the shunt was confirmed visually (mixing of arterial blood in the caval vein). A sham operation was performed in SHR and WKY ( $n=6$ at each time-point) including free dissection of both the aorta and the inferior caval vein. Hence, the sham operation was similar to the ACF surgery, with the exception of the actual vessel puncture.

The degree of ACF was moderate without signs of cardiac failure, as demonstrated by no significant change in liver and lung wet weight to dry weight ratios (data not shown). To confirm the patency of ACF on the day of experimentation, the presence of systolic murmur was checked by auscultation. Only ACF animals showing clear-cut cardiac hypertrophy ( $>2$ S.D. at any time-point) were included in the study. One rat at day 1 both in SHR-sham and SHR-ACF, one rat at day 2 in SHRACF, one rat at day 4 in SHR-sham, one rat at day 2 in WKY-sham, one rat at day 4 in WKY-ACF and one rat from both WKY-sham and WKY-ACF were excluded from the study due to the above exclusion criterion and to unexpected death during surgical procedures.

Radio-telemetry In separate groups of SHR and WKY rats, radio-telemetric transducers (model TA11PA-C40; Data Sciences Inc., St Paul, MN, USA) were implanted 1 week prior to ACF surgery. The catheter of the transducer was placed into the inferior caval vein $(n=4$ for SHR and $n=3$ for $\mathrm{WKY}$ ), and the catheter tip was faced in the proximal direction. The catheter was held in place by adding cyanoacrylate glue. The radio transmission was received by plates (RA1010; Data Sciences Inc) placed directly under the rat's cage, and the digital signal was transferred via a consolidation matrix (BCM100; Data Sciences Inc) to a computer-based data acquisition system (Dataquest IV, Version 4; Data Sciences Inc). Venous pressures were collected on-line at $150 \mathrm{~Hz}$, for $15 \mathrm{~s}$ at 5-min intervals for each animal. CVP was monitored by the Dataquest IV software program and stored for subsequent analysis. The ACF was created at approximately the same level as the telemetry catheter tip. During ACF 
surgery, pressure monitoring was stopped for 30-45 min. CVP was then followed for $16 \mathrm{~h}$.

\section{Experimental protocol}

Experiments were performed on SHR-ACF, SHR-sham, WKY-ACF and WKY-sham rats 1, 2, 4 and 7 days post-operatively. At days 1, 2, 4 and 7, SBP was measured by tail plethysmography (Narco BioSystems, Houston, TX, USA). Following anaesthesia, the rats were weighed and the heart and inferior caval vein excised. The tissue was trimmed free, the heart was separated into LV including septum, and RV and weighed before being snap frozen in liquid nitrogen and stored at $-80^{\circ} \mathrm{C}$.

\section{Molecular biology}

The GH receptor probe The pT7T3 $18 \mathrm{U}$ plasmid contains a $560 \mathrm{bp}$ BamHI fragment of the rat $\mathrm{GH}$ receptor cDNA which encodes the early part of the extracellular domain of the GH receptor and, thus, does not differentiate between the $\mathrm{GH}$ receptor and the GH-binding protein. Antisense GH receptor ${ }^{35} \mathrm{~S}-\mathrm{UTP}$ labelled RNA was synthesised according to the manufacturer's instructions (Promega, Madison, WI, USA).

The IGF-I probe A $153 \mathrm{bp} \mathrm{SmaI} \mathrm{fragment} \mathrm{of} \mathrm{a} \mathrm{genomic}$ subclone of mouse IGF-I (exon 3 by analogy to human IGF-I) subcloned into a pSP64 plasmid was used as a template for probe synthesis (Mathews et al. 1986). The plasmid was linearised with EcoRI and used as template for synthesis of ${ }^{35} \mathrm{~S}-U T P$ labelled IGF-I cRNA with SP6 RNA polymerase according to the manufacturer's instructions (Promega).

The IGF-I receptor probe The RNA probe was synthesised from a $265 \mathrm{bp}$ fragment of the rat IGF-I receptor cDNA subcloned into a plasmid vector pGEM-3 (Werner et al. 1989). The vector was linearised with EcoRI and the rat IGF-I receptor antisense RNA was synthesised using SP6 RNA polymerase and ${ }^{35} \mathrm{~S}-\mathrm{UTP}$. Synthesis of the rat IGF-I receptor sense RNA standard was achieved using BamH1 for linearisation of the plasmid and addition of T7 RNA polymerase.

Solution hybridisation Frozen tissue was homogenised, treated with proteinase-K and total nucleic acids (TNA) were extracted with phenol-chloroform as described previously (Durnam \& Palmiter 1983). A solution hybridisation assay was used to quantify IGF-I, IGF-I receptor and GH receptor mRNAs (Durnam \& Palmiter 1983). The probes were hybridised to TNA samples at $70{ }^{\circ} \mathrm{C}$ for 24 h. After RNase treatment the precipitated protected hybrids were then collected on glass-fibre filters (GF/C Whatman; Whatman International Ltd, Maidstone, Kent, UK) and counted in a scintillation counter. The signal was compared with a standard curve based on known amounts of IGF-I, IGF-I receptor or GH receptor mRNAs. The results were related to the DNA content in the TNA sample (Labarca \& Paigen 1980). The probes have been verified by RNase protection (Guron et al. 1996, Wickman et al. 1997).

\section{Statistical analysis}

Values are given as means \pm S.D. All cardiac weights and mRNA values were found to be normally distributed. The statistically significant difference between groups was analysed by three-way ANOVA followed by Fisher's LSD post-hoc test. Two-tailed unpaired Student's $t$-test was used for telemetry data by averaging CVP $4 \mathrm{~h}$ before and between 2 and $16 \mathrm{~h}$ after ACF surgery, and between strains for the same time-period. A $P$ value less than $0 \cdot 05$ was considered statistically significant.

\section{Results}

Blood pressure

By using the tail-cuff method, all SHR-sham rats showed a statistically significant increase in SBP during the study period compared with WKY-sham $(P<0 \cdot 05$, Fig. 1$)$. The SBP was reduced in both SHR-ACF and WKY-ACF rats during the whole study period compared with their respective sham-operated group $(P<0 \cdot 05$, Fig. 1). The SBP in SHR-ACF decreased to a greater extent than in WKY-ACF, in response to the fistula opening $(P<0 \cdot 05$, Fig. 1). There was no difference in baseline CVP between SHR and WKY pre-ACF, being approximately 3-4 mmHg (Fig. 2). SHR showed a transient increase in CVP from $2.9 \pm 5.1 \mathrm{mmHg}$ before ACF to $6.4 \pm$ $9 \cdot 3 \mathrm{mmHg}$ as averaged over $16 \mathrm{~h}$ following fistula opening $(P<0 \cdot 05)$. CVP returned thereafter to pre-ACF levels (Fig. 2). In contrast, WKY-ACF rats showed similar levels of CVP before and after ACF surgery; $4 \cdot 7 \pm 2 \cdot 2$ vs $5 \cdot 3 \pm 2 \cdot 5 \mathrm{mmHg}$ before and during $16 \mathrm{~h}$ after fistula opening (Fig. 2).

\section{$R V$ weight}

Both sham-operated SHR and WKY groups demonstrated similar RV weights at the studied time-points (Table 1). All ACF rats showed statistically significant increases in $\mathrm{RV}$ weight already by $24 \mathrm{~h}$ after the fistula opening (Table 1, Fig. 3). RV weight increased progressively and to a similar magnitude in both SHR and WKY after ACF surgery compared with their respective sham group (Fig. 3). At day 2, however, SHR-ACF showed a statistically significant greater increase in RV weight compared with WKY-ACF (Table 1, Fig. 3). 


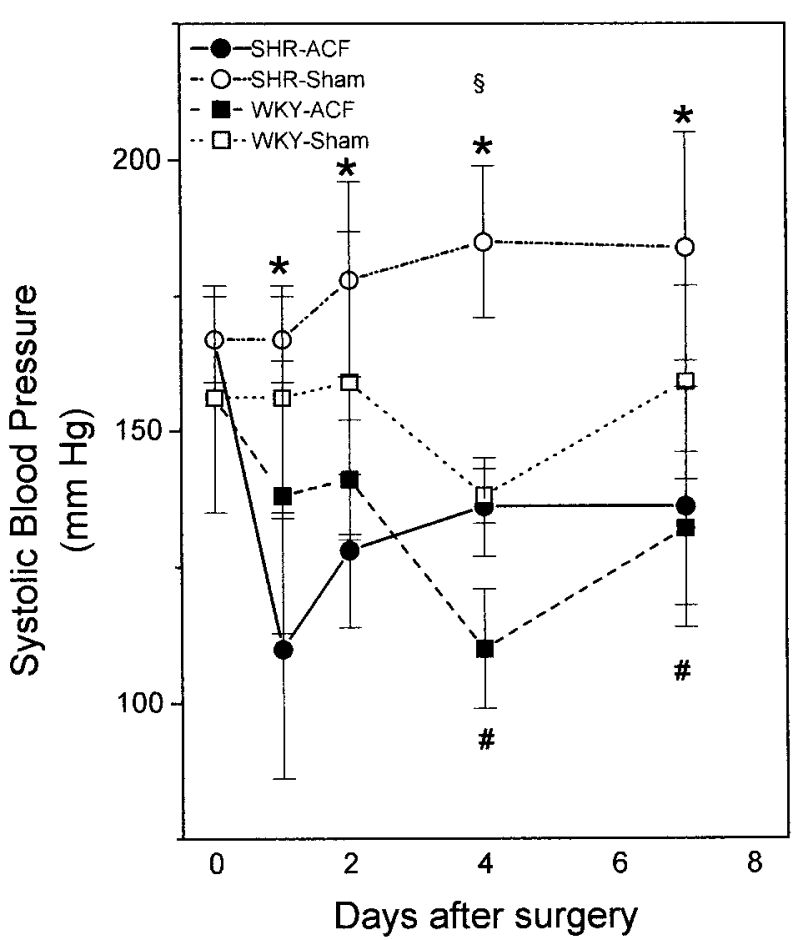

Figure 1 Line plot showing the effect on SBP in response to ACF in SHR $(n=5-6,0)$ and WKY $(n=5-6, \mathbf{\square})$ and in sham-operated SHR $(n=5-6, \bigcirc)$ and WKY $(n=5-6, \square)$. Experiments were performed 1, 2, 4 and 7 days post-surgery. Data are means \pm S.D. A three-way ANOVA showed a statistically significant difference $(P<0 \cdot 05)$ between surgical intervention and strains. ${ }^{\star} P<0 \cdot 05$, SHR-ACF vs SHR-sham; \#P<0.05, WKY-ACF vs WKY-sham; $\S P<0 \cdot 05$, SHR-sham vs WKY-sham during the study period.

\section{IGF-I $m R N A$ expression}

The increased haemodynamic demand caused induction of IGF-I mRNA in both the RV and the caval vein in both groups (Table 1). In SHR-ACF rats, the RV and the caval vein showed a transient and lower IGF-I mRNA expression compared with that in the WKY-ACF group (Table 1, Fig. 4). Similar to the RV IGF-I mRNA expression in the SHR-ACF group, the caval vein showed the highest IGF-I mRNA expression at day 2 after shunt opening (Table 1, Fig. 4). It is our experience that cardiac IGF-I mRNA expression shows some biological variation in sham animals. Although RV IGF-I mRNA in sham WKY at day 4 demonstrated a slightly lower value compared with the other sham IGF-I mRNA values, there was no statistically significant difference either with respect to strain or to time.

\section{GH receptor and IGF-I receptor $m R N A$ s expression}

The volume-loaded WKY rats showed an enhanced expression of both RV GH receptor and IGF-I receptor mRNAs expression vs SHR-ACF rats $(P<0 \cdot 05$, Fig. 5$)$.

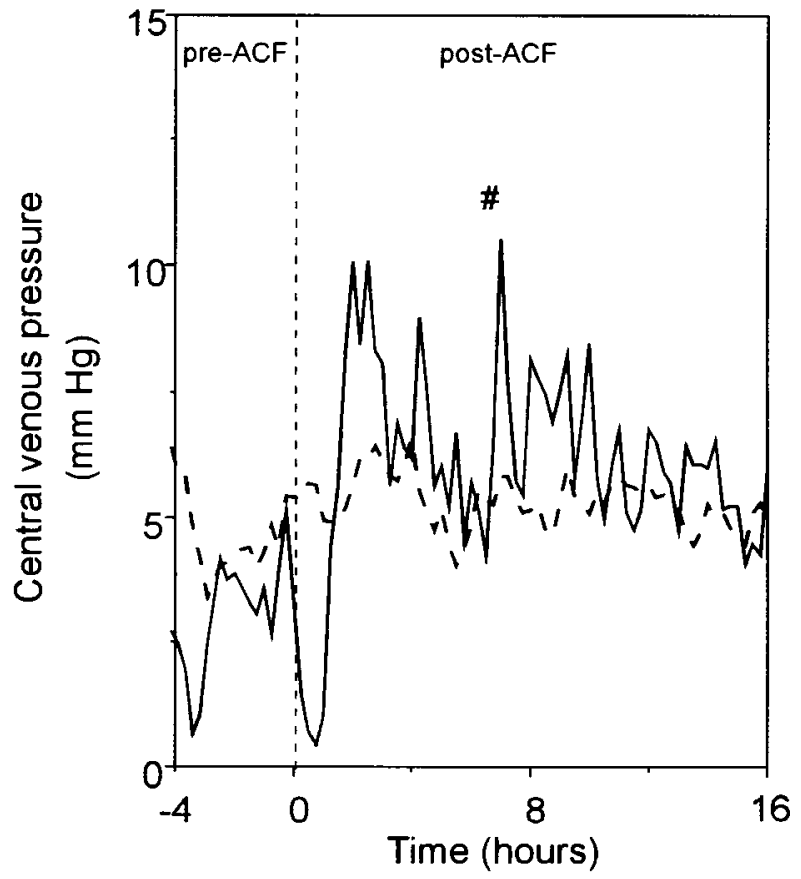

Figure 2 Line plot showing continuous radio-telemetric pressure recordings of CVP before and after induction of ACF in SHR $(n=4$, solid line) and WKY ( $n=3$, broken line). The pressure monitoring was initiated $4 \mathrm{~h}$ pre-surgery and continued up to $16 \mathrm{~h}$ post-surgery. The radio transmission was collected every $15 \mathrm{~min}$. The data collection was stopped for 30 min while ACF was being performed. Data are shown as means \pm S.D. \#In SHR, the average of the CVP from 2 to $16 \mathrm{~h}$ post-surgery was statistically significant $(P<0 \cdot 05)$ compared with the average of the 4-h CVP pre-surgery (unpaired Student's t-test).

There were no changes above control level in RV GH receptor mRNA expression in any of the SHR-ACF rats; it was even reduced at day 7 . Interestingly, in the SHR-sham groups, the expression of RV GH receptor mRNA showed a statistically significant consistent, approximately twofold increase, compared with shamoperated WKY (Table 1). There was, however, a significant elevation of RV GH receptor mRNA expression at day 7 in WKY-ACF rats vs WKY-sham rats (Table 1, Fig. 5). Moreover, there were no changes in RV IGF-I receptor mRNA expression detected at any time-point in the SHR-ACF group, whereas the RV IGF-I receptor mRNA expression in WKY rats increased only at four days after ACF surgery (Table 1, Fig. 5). No change in IGF-I receptor mRNA expression was observed over time in $\mathrm{RV}$ in sham-treated animals.

\section{Discussion}

The main finding of the present study was that a haemodynamic load caused attenuated RV and caval vein 
Table 1 Effects of volume overload by means of ACF in SHR and WKY rats on body and RV weights and mRNA expression of the components of the GH-IGF-I system. Values are means \pm S.D.

\begin{tabular}{|c|c|c|c|c|c|c|c|c|}
\hline & Group & $n$ & $\begin{array}{l}\text { Body } \\
\text { weight } \\
\text { (g) }\end{array}$ & $\begin{array}{l}\text { RV weight } \\
\left(10^{-3} \mathrm{~g} / 100 \mathrm{~g} \text { BW }\right)\end{array}$ & $\begin{array}{l}\text { RV IGF-I } \\
\text { mRNA }\end{array}$ & $\begin{array}{l}\text { RV GH } \\
\text { receptor } \\
\text { mRNA }\end{array}$ & $\begin{array}{l}\text { RV IGF-I } \\
\text { receptor } \\
\text { mRNA }\end{array}$ & $\begin{array}{l}\text { Caval vein IGF-I } \\
\text { mRNA }\end{array}$ \\
\hline Strain & & & & & & & & \\
\hline SHR & ACF & 5 & $173 \pm 5 \S$ & $71 \pm 5 \S^{*}$ & $0 \cdot 46 \pm 0 \cdot 10 \S$ & $2 \cdot 51 \pm 0 \cdot 51 \S$ & $0.95 \pm 0.29 \S$ & $2 \cdot 54 \pm 1 \cdot 13 \S$ \\
\hline SHR & Sham & 5 & $180 \pm 6$ & $58 \pm 8$ & $0 \cdot 35 \pm 0 \cdot 14$ & $2 \cdot 21 \pm 0 \cdot 82 \#$ & $0 \cdot 70 \pm 0 \cdot 22$ & $1 \cdot 94 \pm 0 \cdot 39$ \\
\hline WKY & ACF & 6 & $179 \pm 6$ & $70 \pm 4^{*}$ & $0.36 \pm 0.03$ & $1 \cdot 50 \pm 0 \cdot 25$ & $1 \cdot 06 \pm 0 \cdot 31$ & $3 \cdot 49 \pm 1 \cdot 70$ \\
\hline \multicolumn{9}{|l|}{ Day 2} \\
\hline SHR & ACF & 5 & $179 \pm 11$ & $82 \pm 5^{*}$ & $0 \cdot 50 \pm 0 \cdot 17^{*}$ & $2 \cdot 68 \pm 0 \cdot 65$ & $1 \cdot 02 \pm 0 \cdot 34$ & $3 \cdot 31 \pm 0 \cdot 38^{*}$ \\
\hline SHR & Sham & 6 & $188 \pm 3$ & $60 \pm 5$ & $0.32 \pm 0.08$ & $2 \cdot 76 \pm 0 \cdot 75 \#$ & $0 \cdot 72 \pm 0 \cdot 16$ & $1 \cdot 63 \pm 0.32$ \\
\hline WKY & ACF & 6 & $179 \pm 4$ & $74 \pm 6^{*}$ & $0.51 \pm 0.25^{*}$ & $1 \cdot 17 \pm 0 \cdot 27$ & $0 \cdot 73 \pm 0.13$ & $3 \cdot 58 \pm 1 \cdot 20$ \\
\hline WKY & Sham & 5 & $186 \pm 7$ & $61 \pm 3$ & $0 \cdot 28 \pm 0 \cdot 04$ & $0 \cdot 80 \pm 0 \cdot 01$ & $0.65 \pm 0.07$ & $2 \cdot 71 \pm 1 \cdot 93$ \\
\hline \multicolumn{9}{|l|}{ Day 4} \\
\hline \multicolumn{9}{|l|}{ Day 7} \\
\hline SHR & $\mathrm{ACF}$ & 6 & $196 \pm 15^{*}$ & $85 \pm 3^{*}$ & $0 \cdot 34 \pm 0 \cdot 11$ & $0 \cdot 66 \pm 0.33^{*}$ & $0.67 \pm 0.26$ & $2 \cdot 56 \pm 0.47$ \\
\hline SHR & Sham & 6 & $207 \pm 8^{*}$ & $58 \pm 5$ & $0 \cdot 30 \pm 0 \cdot 13$ & $2 \cdot 06 \pm 1 \cdot 09 \#$ & $0 \cdot 66 \pm 0 \cdot 41$ & $1 \cdot 91 \pm 0 \cdot 76$ \\
\hline WKY & ACF & 5 & $198 \pm 10$ & $83 \pm 2^{*}$ & $0.60 \pm 0.12^{*}$ & $2 \cdot 56 \pm 0.83^{*}$ & $1 \cdot 48 \pm 0.89 *$ & $3 \cdot 78 \pm 0.67^{*}$ \\
\hline WKY & Sham & 5 & $197 \pm 5$ & $56 \pm 5$ & $0 \cdot 32 \pm 0 \cdot 07$ & $0 \cdot 75 \pm 0 \cdot 21$ & $0 \cdot 83 \pm 0 \cdot 70$ & $1 \cdot 08 \pm 0 \cdot 31$ \\
\hline
\end{tabular}

All mRNA values are expressed as $10^{-18} \mathrm{~mol} / 10^{-6} \mathrm{~g}$ DNA.

$\S P<0.05$ between SHR, WKY, ACF and sham considering all time-points. ${ }^{*} P<0.05$ between ACF and sham at the respective time-point.

$\# P<0 \cdot 05$ between SHR-sham and WKY-sham at the respective time-point.

mRNA induction of IGF-I, its receptor and GH receptor in SHR compared with WKY. These were also turned off more quickly. The biological and functional hypertrophic response in the RV in SHR was, however, similar to that in WKY rats, suggesting an increased growth response for a given IGF-I mRNA activation in the former. An advantage in the present study was that both strains started with similar RV weights and CVP and, after the induction of the fistula, SHR showed a faster onset of RV hypertrophy and a transient elevation of venous pressure. The latter phenomenon may be related to the faster onset of IGF-I mRNA induction noted in the inferior caval vein 2 days following fistula opening. Over the 7-day experimental period, SBP fell to a greater extent in SHR vs WKY, probably reflecting a more hyperkinetic circulation in the former. This suggests that SHR require less GH-IGF-I system activation to yield a given amount of RV structural adaptation compared with WKY, which may be explained by an inherent increase in the GH-IGF-I system sensitivity in the heart and vasculature. An alternative explanation could be that the GH-IGF-I axis is of limited importance for the haemodynamic structural adaptation of the cardiovascular system in SHR compared with other trophically acting agents, such as platelet-derived growth factor or TGF- $\beta$. One may also argue, however, that the different haemodynamic response to ACF in the two strains may have influenced the various gene expressions, since the SHR-ACF group showed a more prominent blood pressure fall compared with the WKY fistula group.

When a fistula is created between abdominal aorta and inferior caval vein in normotensive rats the low-pressure compartment will be exposed to a sustained increase of volume flow and a consequent decrease of arterial blood pressure and total peripheral resistance as well as an increase of right atrial pressure (Huang et al. 1992, 1994, Ruzicka et al. 1993, Ruzicka \& Leenen 1995), but without concurrent changes in CVP (Wickman et al. 1997). When this ACF model was applied to SHR, there was an immediate, transient increase in CVP, which did not occur in WKY, probably reflecting a greater volume flow across the fistula for the first few hours. These haemodynamic changes in the SHR-ACF will, in turn, also activate neurohumoral factors, and apparently to an even greater extent than in WKY-ACF rats (Oka et al. 1993), corroborating our data showing evidence for a greater fistula volume flow in SHR vs WKY. However, the present study showed that the CVP had already normalised within 12 to $16 \mathrm{~h}$ after fistula opening in SHR, suggesting a haemodynamic profile more like the one in WKY for the remaining study period. 


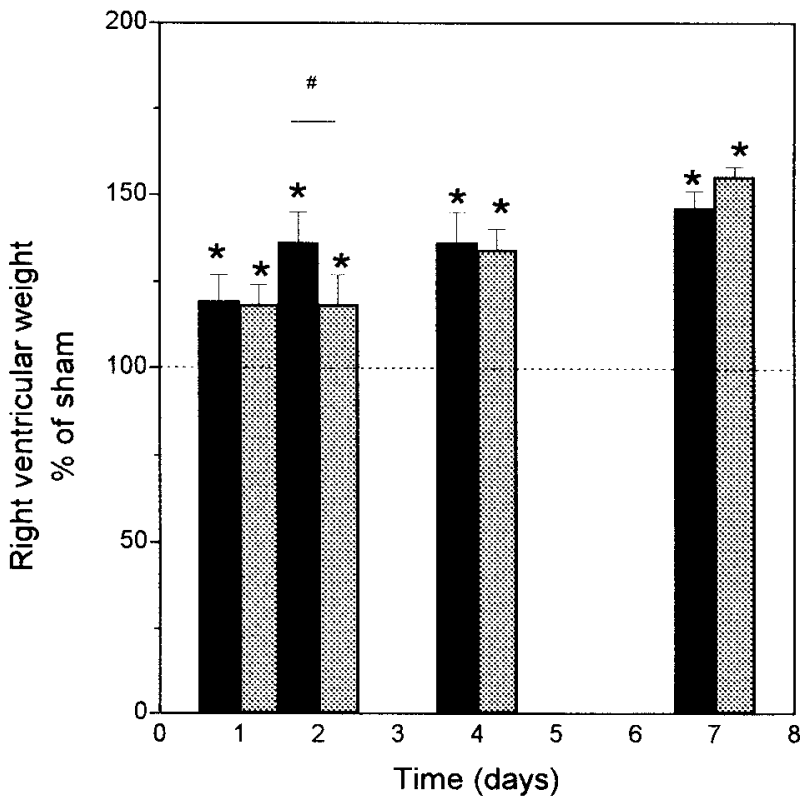

Figure 3 Bar graphs showing the relative effect on RV weight vs sham in response to ACF in SHR ( $n=5-6$, solid bars) and WKY ( $n=5-6$, shaded bars). Sham-operated rats from each strain served as controls. Experiments were performed 1, 2, 4 and 7 days post-surgery. Data are means \pm S.D. A three-way ANOVA showed a statistically significant difference $(P<0.05)$ between surgical intervention and time in both strains. ${ }^{*} P<0.05$ between ACF and sham-operation for the respective strain, $\# P<0.05$ between SHR and WKY. The relative increase of RV weight at day 2 was $51 \%$ in SHR-ACF vs WKY-ACF $(P<0 \cdot 05)$.

The mechanisms for transforming a mechanical stimulus, due to augmented volume/pressure load on the heart and vessels, into a structural growth response are unclear, although several factors, such as immediate/early growth markers/factors (e.g. proto-oncogenes (Schunkert et al. 1991) and TGF- $\beta$ (Komoro et al. 1991)) and early/late growth factor systems (e.g. GH-IGF-I) have been shown to be involved (Wåhlander et al. 1992, Fath et al. 1993, Donohue et al. 1994, Delafontaine 1995, Guron et al. 1996). Thus, there is compelling evidence for the importance of the GH-IGF-I system, not only in the regulation of physiological adaptive cardiovascular hypertrophy, but it has also a role in the failing and infarcted myocardium (Fazio et al. 1996, Isgaard et al. 1997). The present study demonstrated IGF-I mRNA over-expression in two different tissues, the RV and the caval vein after induction of ACF, supporting previous findings in normotensive rats (Isgaard et al. 1994, Wickman et al. 1997). Surprisingly, both strains showed a rapid and substantial increase in RV weight in response to ACF surgery, being approximately $20 \% 24 \mathrm{~h}$ after shunt induction. Given that the GH-IGF-I system was not increased above control level during the initial $24 \mathrm{~h}$, other systems must also be involved in generating growth (vide supra). Apparently, IGF-I mRNA expression comes into play in a later phase in the chain of growth factor events, here being over-expressed at $48 \mathrm{~h}$ after fistula induction in both cardiac and vascular tissues (Fig. 3).

Although several in vitro studies have provided evidence for an increased proliferative response in SHR VSMC vs WKY (Bukoski et al. 1991, Hamet et al. 1991, Saltis \& Bobik 1992, Saltis et al. 1992a,b, 1993, Tremblay et al. 1992, Agrotis et al. 1993, Grammas et al. 1994, Sato et al. 1995), Dilley et al. (1994) showed that renal hypertensive SHR exhibited a greater LV hypertrophic response and an augmented resistance vessel structural adaptation than was the case for WKY-2K1C, despite a smaller blood pressure increase in the former, suggesting that SHR are more prone to respond to a given haemodynamic challenge. However, their study design included vessels and LVs
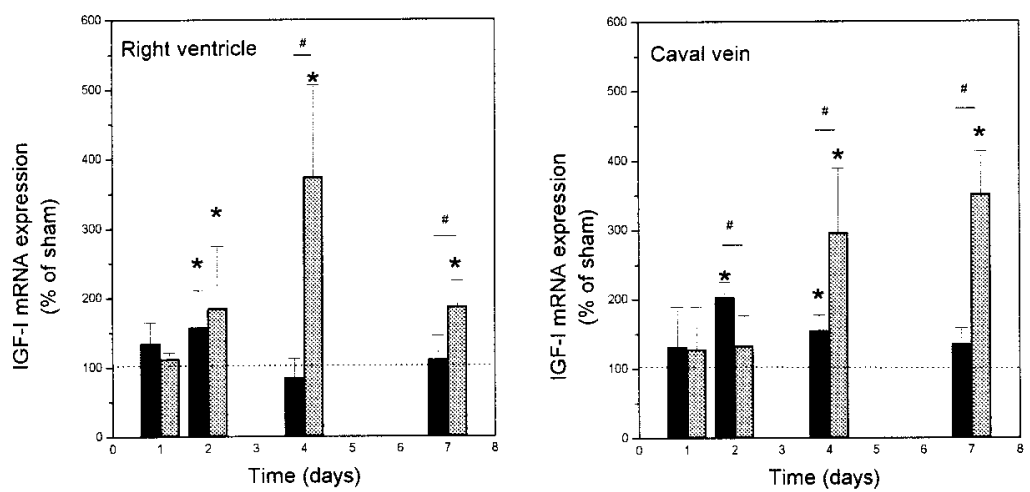

Figure 4 Bar graphs showing the IGF-I mRNA expression changes in RV (left panel) and in caval vein (right panel) in SHR ( $n=5-6$, solid bars) and WKY ( $n=5-6$, shaded bars) after induction of ACF). Sham-operated rats from each strain served as controls. The experiments were performed 1, 2, 4 and 7 days after surgery. In both panels, a statistically significant difference was shown between strain, surgical intervention and time (three-way ANOVA, $P<0 \cdot 05$ ). Data are means \pm S.D. ${ }^{*} P<0 \cdot 05$ between ACF and sham for the respective strain. $\# P<0 \cdot 05$ between SHR and WKY. 

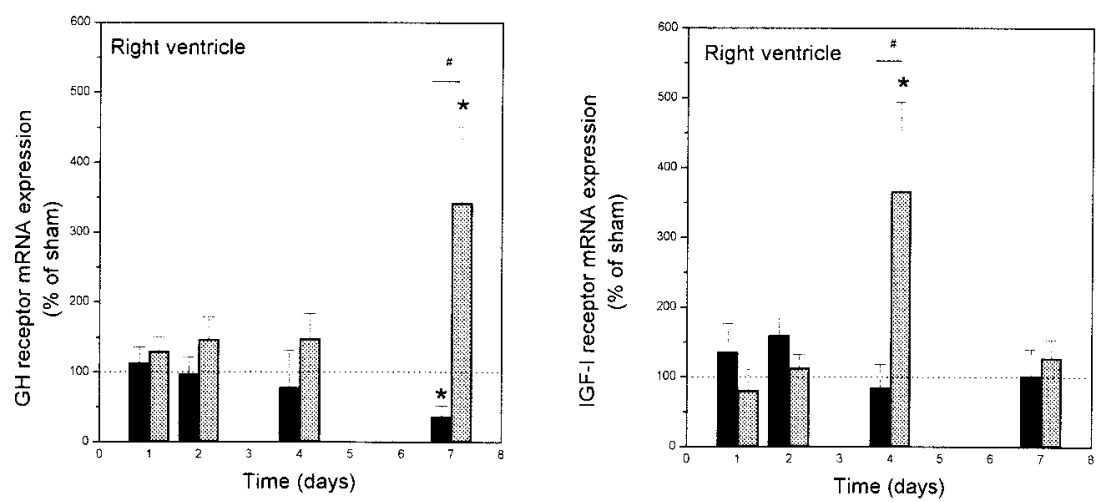

Figure 5 Bar graphs showing the GH receptor (left panel) and IGF-I receptor (right panel) mRNA expression changes in RV in SHR ( $n=5-6$, solid bars) and WKY ( $n=5-6$, shaded bars) after induction of ACF. Sham-operated rats from each strain served as controls. The experiments were performed 1, 2, 4 and 7 days after surgery. In both panels, a statistically significant difference was shown between strains, surgical intervention and time (three-way ANOVA, $P<0 \cdot 05)$. Data are means \pm S.D. ${ }^{*} P<0 \cdot 05$ between ACF and sham for the respective strain. $\# P<0.05$ between SHR and WKY.

obtained from SHR that were already adapted structurally to an elevated work load, prior to the induction of the superimposed renal hypertension. Our approach, however, was to utilise non-haemodynamically challenged SHR tissues: the RV and the caval vein. Our in vivo results, showing less activation of the GH-IGF-I system in SHR for a given amount of RV hypertrophy thus agree with the conclusion put forward by Dilley et al. (1994).

The present study demonstrated over-expression of GH receptor mRNA after the peak of IGF-I and IGF-I receptor mRNAs in volume-overloaded WKY rats, whereas the SHR-ACF group showed unchanged levels of GH receptor mRNA expression during haemodynamic overload. The reason for the elevated cardiac GH receptor expression observed in the WKY group and also previously (Isgaard et al. 1994, Guron et al. 1996, Wickman et al. 1997) is unclear, although it may indicate that the IGF-I gene expression response, and the subsequent protein synthesis, are not enough to create a sufficient adaptive hypertrophy in normotensive strains. Interestingly, the SHR-ACF group demonstrated no such elevation of RV GH receptor mRNA. This could be due to the fact that sham-treated SHR showed a twofold higher baseline level of RV GH receptor mRNA compared with WKY-sham, which may be sufficient to contribute to the adaptive RV growth response in this model of haemodynamic overload. However, it should be noted that it is presently not known if these increased levels of GH receptor mRNA are accompanied by an increase of functional GH receptors.

The present study also demonstrated a marked increase of the IGF-I receptor in the RV 4 days after surgery in WKY rats, but a lack of increased expression of RV IGF-I receptor mRNA in SHR-ACF. This suggests, at least in the normotensive strain, that an elevation of the IGF-I receptor mRNA expression would enhance the response to locally available IGF-I in the RV and contribute to the hypertrophic response, in agreement with the rapid and transient IGF-I receptor gene induction in the 2K1C hypertension (Guron et al. 1996). However, whether the up-regulation of the IGF-I receptor gene expression during these haemodynamic challenges results in an increased number of receptors remains to established.

One limitation of this study is that we have, so far, only measured mRNA levels of components of the GH-IGF-I axis. However, a previous study from our group has demonstrated an accompanying increase in IGF-I protein when IGF-I gene expression is up-regulated during development of cardiac hypertrophy (Wåhlander et al. 1992) and in the caval vein (Wickman et al. 1997).

Another limitation is that the present study was focused on the GH-IGF-I axis, and we are aware that other growth-related systems may be of equal or even more importance for the development of adequate structural cardiac growth in response to a haemodynamic overload. The opportunity for studying other growth factors in this experimental setting is somewhat difficult, since the amount of tissue from the caval vein and RV are restricted.

In summary, ACF volume-overloaded SHR showed a consistently lower magnitude of RV and vascular IGF-I mRNA induction than that observed in the volumeoverloaded WKY rats. The resultant RV hypertrophy was pronounced in both strains and it developed to a similar degree by the end of the study, indicating that IGF-I may be at least of some importance for the development of cardiovascular hypertrophy in both normotensive and hypertensive rats. One may speculate that the SHR possibly require less GH-IGF-I system activation for 
creating an adaptive hypertrophic growth compared with the WKY rat, at least for the myocardial and venous tissues in this model of volume overload.

\section{Acknowledgements}

The assistance of Camilla Brantsing and Gunnel Andersson is greatly appreciated. This study was supported by the Swedish Medical Research Council (450, 2265, 9047, 11133), the Swedish Heart and Lung Foundation, Magnus Bergvall Foundation, Åke Wibergs Foundation, the Swedish Society for Medical Research, the Lundberg Foundation, Pharmacia and Upjohn, Stockholm, Göteborg Medical Society, the Anna Ahrenberg Foundation and the Committee for Research and Development in Health and Caring Science, Göteborg University College and Göteborg University.

\section{References}

Adams MA, Bobik A \& Korner PI 1989 Differential development of vascular and cardiac hypertrophy in genetic hypertension. Relation to sympathetic function. Hypertension 14 191-202.

Agrotis A, Bray PJ, Saltis J \& Bobik A 1993 Vascular smooth muscle cell proliferation in SHR and WKY rats: evidence for specific differences in growth inhibitory regulatory mechanisms. Clinical and Experimental Pharmacology and Physiology 20 327-330.

Bukoski RD, DeWan P \& Bo J 1991 Mechanism of the enhanced epidermal growth factor-induced growth response of genetically hypertensive vascular myocytes. Circulation Research 69 757-764.

Delafontaine P 1995 Insulin-like growth factor I and its binding proteins in the cardiovascular system. Cardiovascular Research $\mathbf{3 0}$ 825-834.

Dilley RJ, Kanellakis P, Oddie CJ \& Bobik A 1994 Vascular hypertrophy in renal hypertensive spontaneously hypertensive rats. Hypertension 24 8-15.

Donohue TJ, Dworkin LD, Lango MN, Fliegner K, Lango RP, Benstein JA, Slater WR \& Catanese VM 1994 Induction of myocardial insulin-like growth factor-I gene expression in left ventricular hypertrophy. Circulation 89 799-809.

Durnam DM \& Palmiter RD 1983 A practical approach for quantitating specific mRNAs by solution hybridization. Analytical Biochemistry 131 385-393.

Fath KA, Alexander RW \& Delafontaine P 1993 Abdominal coarctation increases insulin-like growth factor-I mRNA levels in rat aorta. Circulation Research 72 271-277.

Fazio S, Sabatini D, Capaldo B, Vigorito C, Giordano A, Guida R, Pardo F, Biondi B \& Sacca L 1996 A preliminary study of growth hormone in the treatment of dilated cardiomyopathy. New England Journal of Medicine 334 809-814.

Folkow B 1982 Physiological aspects of primary hypertension. Physiological Reviews 62 347-504.

Friberg P 1985 Structural and functional adaptation in the rat myocardium and coronary vascular bed caused by changes in pressure and volume load. Acta Physiologica Scandinavica (Suppl) 540 $1-47$.

Friberg P \& Nordborg C 1986 Functional, morphological and metabolic characteristics of isolated hearts from normotensive and spontaneously hypertensive rats before, during and after renal hypertension. Acta Physiologica Scandinavica 126 161-171.

Friberg P, Isgaard J, Wahlander H, Wickman A, Guron G \& Adams MA 1995 Cardiac hypertrophy and related growth processes: the role of insulin-like growth factor-I. Blood Pressure (Suppl) 2 22-29.
Garcia R \& Diebold S 1990 Simple, rapid, and effective method of producing aortocaval shunts in the rat. Cardiovascular Research $\mathbf{2 4}$ 430-432.

Grammas P, Diglio C, Giacomelli F \& Wiener J 1994 Growth properties and receptor expression in vascular smooth muscle cells from hypertensive rats. Clinical and Experimental Hypertension 16 207-227.

Guron G, Friberg P, Wickman A, Brantsing C, Gabrielsson B \& Isgaard J 1996 Cardiac insulin-like growth factor-I and growth hormone receptor expression in renal hypertension. Hypertension 27 636-642.

Hadrava V, Tremblay J \& Hamet P 1989 Abnormalities in growth characteristics of aortic smooth muscle cells in spontaneously hypertensive rats. Hypertension 13 589-597.

Hamet P, Hadrava V, Kruppa U \& Tremblay J 1991 Transforming growth factor beta 1 expression and effect in aortic smooth muscle cells from spontaneously hypertensive rats. Hypertension $\mathbf{1 7}$ 896-901.

Huang M, Hester RL \& Guyton AC 1992 Hemodynamic changes in rats after opening an arteriovenous fistula. American Journal of Physiology $262 \mathrm{H} 846-\mathrm{H} 851$.

Huang M, LeBlanc MH \& Hester RL 1994 Evaluation of the needle technique for producing an arteriovenous fistula. Journal of Applied Physiology 77 2907-2911.

Isgaard J, Wåhlander H, Adams MA \& Friberg P 1994 Increased expression of growth hormone receptor mRNA and insulin-like growth factor I mRNA in volume-overloaded hearts. Hypertension 23 884-888.

Isgaard J, Kujacic V, Jennische E, Holmäng A, Sun XY, Hedner T, Hjalmarson A \& Bengtsson BA 1997 Growth hormone improves cardiac function in rats with experimental myocardial infarction. European Journal of Clinical Investigation 27 517-525.

Ito H, Hiroe M, Hirata Y, Tsujino M, Adachi S, Shichiri M, Koike A, Nogami A \& Marumo F 1993 Insulin-like growth factor-I induces hypertrophy with enhanced expression of muscle specific genes in cultured rat cardiomyocytes. Circulation 87 1715-1721.

Komoro I, Katoh Y, Hoh E, Takaku F \& Yazaki Y 1991 Mechanisms of cardiac hypertrophy and injury: possible role of protein kinase C activation. Japanese Circulation Journal 55 1149-1157.

Korner PI, Bobik A, Angus JA, Adams MA \& Friberg P 1989 Resistance control in hypertension. Journal of Hypertension (Suppl) 7 S125-S134.

Labarca C \& Paigen KA 1980 Simple, rapid and sensitive DNA assay procedure. Analytical Biochemistry 102 344-352.

Lever AF \& Harrap SB 1992 Essential hypertension: a disorder of growth with origins in childhood? Journal of Hypertension $\mathbf{1 0}$ 101-120.

Mathews LS, Norstedt G \& Palmiter RD 1986 Regulation of insulin-like growth factor-I gene expression by growth hormone. Proceedings of the National Academy of Sciences of the USA 83 9343-9347.

Mulvany MJ, Baandrup U \& Gundersen HJ 1985 Evidence for hyperplasia in mesenteric resistance vessels of spontaneously hypertensive rats using a three-dimensional disector. Circulation Research 57 794-800.

Oka T, Nishimura H, Ueyama M, Kubota J \& Kawamura K 1993 Haemodynamic and neurohumoral changes in spontaneously hypertensive rats with aortocaval fistulae. Clinical Science $\mathbf{8 4}$ 531-535.

Owens GK \& Schwartz SM 1982 Alterations in vascular smooth muscle mass in the spontaneously hypertensive rat. Role of cellular hypertrophy, hyperploidy, and hyperplasia. Circulation Research $\mathbf{5 1}$ 280-289.

Ruzicka M \& Leenen FHH 1995 Relevance of blockade of cardiac and circulatory angiotensin-converting enzyme for the prevention of volume overload-induced cardiac hypertrophy. Circulation 91 16-19.

Ruzicka M, Yuan B, Harmsen E \& Leenen FHH 1993 The renin-angiotensin system and volume overload-induced cardiac 
hypertrophy in rats. Effects of angiotensin converting enzyme inhibitor versus angiotensin II receptor blocker. Circulation $\mathbf{8 7}$ 921-930.

Saltis J \& Bobik A 1992 Vascular smooth muscle growth in genetic hypertension: evidence for multiple abnormalities in growth regulatory pathways. Journal of Hypertension 10 635-643.

Saltis J, Agrotis A \& Bobik A 1992a TGF-beta 1 potentiates growth factor-stimulated proliferation of vascular smooth muscle cells in genetic hypertension. American Journal of Physiology 263 C420-C428.

Saltis J, Agrotis A \& Bobik A $1992 b$ Differential regulation by transforming growth factor-beta 1 of platelet-derived growth factor-stimulated proliferation of vascular smooth muscle cells from SHR and WKY rats. Clinical and Experimental Pharmacology and Physiology 19 396-399.

Saltis J, Agrotis A \& Bobik A 1993 Differences in growth characteristics of vascular smooth muscle from spontaneously hypertensive and Wistar-Kyoto rats are growth factor dependent. Journal of Hypertension 11 629-637.

Sato M, Ohsaki Y \& Tobise K 1995 Transforming growth factorbeta 1 proliferated vascular smooth muscle cells from spontaneously hypertensive rats. American Journal of Hypertension 8 160-166.

Schunkert H, Jahn L, Izumo S, Apstein CS \& Lorell BH 1991 Localization and regulation of $\mathrm{c}$-fos and c-jun protooncogene induction by systolic wall stress in normal and hypertrophied rat hearts. Proceedings of the National Academy of Sciences of the USA $\mathbf{8 8}$ 11480-11484.
Scott Burden T, Resink TJ, Baur U, Burgin M \& Buhler FR 1989 Epidermal growth factor responsiveness in smooth muscle cells from hypertensive and normotensive rats. Hypertension 13 295-304.

Tremblay J, Hadrava V, Kruppa U, Hashimoto T \& Hamet P 1992 Enhanced growth-dependent expression of TGF beta 1 and hsp70 genes in aortic smooth muscle cells from spontaneously hypertensive rats. Canadian Journal of Physiology and Pharmacology 70 565-572.

Wåhlander H, Isgaard J, Jennische E \& Friberg P 1992 Left ventricular insulin-like growth factor-I increases in early renal hypertension. Hypertension 19 25-32.

Werner H, Woloschak M, Adamo M, Shen Orr Z, Roberts CT Jr \& LeRoith D 1989 Developmental regulation of the rat insulin-like growth factor-I receptor gene. Proceedings of the National Academy of Sciences of the USA 86 7451-7455.

Wickman A, Friberg P, Adams MA, Matejka GL, Brantsing C, Guron G \& Isgaard J 1997 Induction of growth hormone receptor and insulin-like growth factor-I mRNA in aorta and caval vein during hemodynamic challenge. Hypertension 29 123-130.

Received 10 February 1998

Revised manuscript received 3 August 1998

Final revision received 21 December 1998

Accepted 5 January 1999 